\title{
Three Dimensional Modeling and Animation of a New Maglev Ship and Its Study with Computer Vision
}

\author{
Kuldip Acharya \\ National Institute of Technology Agartala, \\ Department of Computer Science and Engineering, Barjala, Jirania, West Tripura, Pin: 799046, INDIA \\ Email: kuldip.acharjee@gmail.com \\ Dr. Dibyendu Ghoshal \\ National Institute of Technology Agartala, \\ Department of Electronics and Communication Engineering, Barjala, Jirania, Tripura, Pin: 799046, INDIA \\ Email: tukumw@gmail.com
}

Received: 17 July 2017; Accepted: 22 September 2017; Published: 08 May 2018

\begin{abstract}
This In the present study, a new type of ship is designed based on the theory of magnetic levitation (Maglev). The structural layout of the proposed ship is modified to adopt the maglev technology. The objective of designing this ship is to assist merchandise and travelers over a long distance in a short period of time. The design and size of this ship is made in such a manner that it has got airplanes landing and take-off facility. According to the theory of magnetic levitation, it travels with negligible friction (ideally frictionless) on a magnetic guideway with high speed and expected safety. An electro-dynamic suspension (EDS) system for magnetic levitation has been used and it would reduce friction on a large scale and generate strong force for both lifting and propulsion purposes and it would also allow the very high speed of travel. High-temperature superconductor (HTS) wires with cryogenic structure are utilized as a part of the configuration of a couple of segments of the maglev ship. The attraction and repulsion force between superconductor magnets and permanent electromagnets are the key factors behind such operation. Computer vision study helps to track the moving object to find whether the object is moving or not. The proposed method has been found to give the acceptable result to identify the moving object.
\end{abstract}

Index Terms-Autodesk Maya, Computer Vision, Computer Animation, Maglev Ship.

\section{INTRODUCTION}

The conventional high-speed ship cannot move with the speed which electrodynamic suspension (EDS) based [1] maglev rail can generate. On the other hand, maglev rails have no facility for airplane take-off or landing despite using EDS system, it has the capacity to take a huge load on it. The biomimetic underwater vehicle with magnetic levitation technology has limited capacity to take huge loads regarding passengers [2]. M-2000 vehicles can carry 12,000 passengers [3] but have no facility for aircraft landing and take-off. To get rid of these problems, design of a maglev theory-based water vehicle has become essential. Here, the design of the conventional ship and maglev technology serve together for offering better service. It is intended to give better facility to the aircraft for both landing and take-off from this proposed maglev ship during emergency period along with traveling with a large number of passenger in a short time. The main purpose of the proposed maglev ship is to take huge loads through the application of EDS system, and the maglev force is capable to reach this high level by enhancing the operating current. In addition to it, the ship can act as a warship such that it can facilitate the take-off and landing of bomber airplanes. The ship structure can also help in carrying missiles especially mid-range ones with a flexibility of varying distance to throw any weapons. The only constraint is the cost involved in it. The proposed system is explained with computer vision system. Kalman filter [4] algorithm is used to detect multiple objects in motion. The principle of this filter is applied to track the moving maglev ship. A conceptual three-dimensional model is designed and animation of the same is done in Autodesk Maya software [5].

\section{RELATED WORK}

The electro-dynamic suspension (EDS) system of maglev mechanism enables the maglev train to achieve very high speed [6] (603 km/hour) and to take heavy load capacity. Magnetic shielding makes the passenger with pacemakers or magnetic data storage media in a safe manner from the adverse effect of strong magnetic fields on the maglev train. The only limitation of EDS maglev train is the cost of the cryogenic cooling system [7] to 
maintain the superconductivity. Superconducting wires are utilized to manufacture the superconducting magnet. The superconducting wire can conduct much larger electric currents than conventional cables. Cryogenic temperatures are required to keep the superconducting magnet in cool condition. Type-II superconducting magnets can produce various types of magnetic field. Neodymium (Nb3) superconducting material produces critical magnetic fields of approximately 44 Tesla [8]. It is cheaper to operate because no energy is lost in the windings. A super-thin 3-inch superconductor plate can suspend something having 70,000 times of its own weight because of the quantum locking phenomenon. A twomillimeter-thin superconducting layer plate can carry 1,000 kilograms of weight e.g., a small car [9]. Japan's superconducting Maglev train developed the Linear Motor Propulsion Railway System in 1962 by the Japan National Railway Company. The Yamanashi Maglev test examination committee is developed by the Ministry of Transport to promote the Japan Railway Construction Public Corporation, JR Central, and the Railway Technical Research Institute. Proposed Japan's superconducting Maglev train developed a Maglev train [10] which run more than $500 \mathrm{~km} / \mathrm{h}$ with a linear synchronous motor and tested on the Yamanashi Maglev in 1997. The magnetic levitation (Maglev) is a frictionless train technology which is environmentfriendly, light-weight, convenient, compact, low maintenance, rapid speed, safe and reliable [11]. The Maglev train utilized electromagnets, superconductors, and levitates on the guideway by generating propulsion force electromechanically and electrodynamically without any physical contact unlike conventional train drives forward by using friction between wheels and rails. The proposed SupraTrans [12] an innovative transportation concept based on the principle of superconductive magnetic levitation. The objective of the proposed system is to developed a system, which has the ability for fast, safe, and reliable transportation experience. The SupraTrans technology uses the flux pinning to stabilize the vertical position of the vehicle utilizing the high-temperature superconductors (HTS). Hermann Kemper of Germany patented the Maglev train in 1934. In the Sixties the Maglev has been improved.th of the Nineties, finally engaging in sensible public carrier in 2003 in Shanghai, China [1]- [4]. In comparison to conventional rail, the Maglev train gives many advantages over the conventional wheeled rail system i.e. its provides low maintenance costs; the guideway construction cost is low; noise and vibration is low.

\section{Proposed Design of MagleV ShIP}

In the proposed system, electrodynamic suspension (EDS) type of magnetic levitation (maglev) technology is used to generate the lifting force to enable the ship to float and to create dynamic stability of the ship for avoiding flips and slides. Superconductors are used in the system to realize levitation. The ship is levitated by the repulsive force created between the superconducting magnets fixed on the ship body and the strong permanent magnets on the track. Theoretically, the superconductor can pass a significant amount of currents, and this is sufficient to run the maglev ship. The ship can move forward by the action of attractive force and the opposing force generated by the magnetic fields. Both the propulsion coils and levitation coils are used in the system to push and pull and to levitate the ship. High-temperature type-II superconducting magnets are proposed to utilize in the ship. Bismuth strontium calcium copper oxide (BSCCO) [13] is a hightemperature type-II superconductor. The EDS maglev systems are normally found to be dynamically stable. When the EDS maglev ship has to slow down its speed, the induced current should be reduced accordingly. The designed ship is provided with auxiliary wheels to support the ship until it reaches departure or landing area. Changing the intensity of the current, the speed of the ship may be controlled. In the proposed system, the cryogenic system is used to maintain the superconductivity. There is provision to keep an uninterrupted supply of electrical power with longer time battery backup to accommodate any power failure. The basic framework of the maglev track would be made up of high-grade steel coated with polyvinyl plastic to avoid corrosion caused due to saline water of the sea. In cases of emergency, the passengers can be rescued with the help of airplane kept on the ship. Fig. 1, shows how the maglev EDS system propels the maglev ship. The magle1v ship is moved forward by the generated attractive and repulsive magnetic fields between the superconducting magnets fixed in the ship body and strong permanent magnets fixed on the guiding walls.

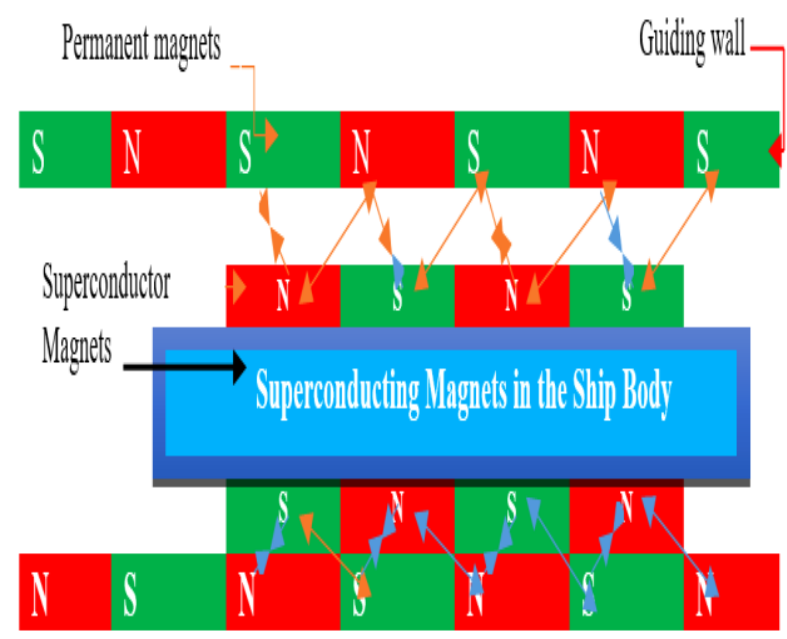

Fig.1. Diagram of EDS maglev ship propulsion by propulsion coil.

\section{Mathematical Calculation AND AnAlysis}

A. The mathematical basis of the dynamics of the proposed magnetic levitation based ship can be described in the following manner

The following symbols have been used for the calculation of required levitation force, 
$\mathrm{m}_{1}, \mathrm{~m}_{2}=$ masses of the levitating ship and $\mathrm{g}=$ acceleration due to the gravity of the earth $\mu=$ permeability of the vacuum space, Henry/m $r=$ distance between the center of the masses

$\mathrm{I}_{\mathrm{c}}=$ current in the coil

$\mathrm{N}=$ number of turn in the coil

$1=$ length of wire

$\mathrm{B}=$ magnetic field, Tesla

$\mathrm{R}=$ wire resistance

$\mathrm{F}=$ force

$\mathrm{d}=$ air drag

$\mathrm{BA}=$ magnetic flux

$\alpha=$ Alpha, environmental effect may degrade the transportation performance like wind flow may disturb the levitation operation. So here $\alpha$, a smoothing factor is introduced for the optimal performance of the proposed maglev transportation.

Table I. Maglev ship different components and their values.

\begin{tabular}{|l|l|}
\hline Maglev Ship Components & $\begin{array}{l}\text { Guesstimate properties approximate } \\
\text { values. }\end{array}$ \\
\hline Ship body & $\begin{array}{l}\text { Steel, iron, plastic, wood, aluminum, } \\
\text { fiberglass, and so forth. }\end{array}$ \\
\hline $\begin{array}{l}\text { Ship Dimension Length, } \\
\text { width, height }\end{array}$ & 1000 foot, 100 feet, 50 feet. \\
\hline Track & $\begin{array}{l}27 \text { miles long. Made of strong } \\
\text { permanent magnets, steel, and iron. }\end{array}$ \\
\hline Pillars height and number & 150 meters. 7000 pillars \\
\hline Speed & 400 km/hour \\
\hline Type of superconductor & $\begin{array}{l}\text { Type-II superconductor made on } \\
\text { BSCCO. Critical temperature (Tc) is } \\
110 \text { Kelvin. Critical Magnetic Field } \\
\text { Bc }>=15 \text { Tesla }\end{array}$ \\
\hline Permanent magnets & Neodymium magnets \\
\hline
\end{tabular}

The generated voltage by Faradays Law,

$$
\text { Voltage generated }=-\mathrm{N} \Delta(\mathrm{BA}) / \Delta \mathrm{t}
$$

The levitating magnetic force is calculated applying the Lorentz force law considering the current in the coil $\left(I_{c}\right)$, the length of wire (1), magnetic field (B) and permeability of the vacuum $(\mu)$.

$$
F=\frac{I_{c} l B^{2}}{2 \mu_{0}}
$$

Attractive and repulsive force to propel the ship:

$$
\frac{G\left(m_{1}, m_{2}\right)+d+\alpha}{r^{2}+\mu_{0}+I_{c} B^{2}}
$$

Inclement weather may degrade the overall performance of the transportation system. Here $\alpha$, is a smoothing parameter to calculate the effect of environmental effects like rain, thunder, lightning or a heavy storm and so on. Here ' $r$ ' is the distance between the center of the masses. $I_{c}$, is the current in the coil and ' $\mathrm{B}$ ' is the magnetic field in Teslas. Suppose the approximate weight of the ship is $\mathrm{w}=2200$ pounds. The acceleration of gravity is $\mathrm{g}=32.2 \mathrm{ft} . / \mathrm{s} 2$.

Now, $m=w / g$

$$
g=32.2, m=\frac{2200}{32.2}
$$

This gives the mass of the ship which can be calculated as $\mathrm{m}=68.32 \mathrm{Kg}$.

Now the force to levitate the proposed magnetically levitate ship can be defined as:

$$
\frac{s w+p w+f w+\alpha}{g+2 \mu_{0}+r^{2}+F}
$$

where,

sw $=$ ship weight

$\mathrm{pw}=$ passenger weight

$\mathrm{fw}=$ freight weight

Here F implies Lorentz force formula,

$\alpha=$ a smoothing factor with a value between 0 and 1 .

$\mathrm{F}=\mathrm{IL} \times \mathrm{B}$

Thus, applying all the five equations, the necessary levitation force, attractive and a repulsive force are calculated for the proposed maglev ship. Here Electrodynamic magnetic levitation with the hightemperature superconductor is used for smooth performance. It is expected that the system will be able to take a load of missile and another weapon during warfare and can maintain a high balance to its normal operation to avoid tilting.

\section{Proposed DEsIGN}

Autodesk Maya student edition software is used in the 3D design and animation of the maglev ship and to Illustrate the entire system, operation, and its natural environment. Fig. 2-6, show different parts of the maglev ship, i.e., a maglev track built on the sea where the ship will travel through floating over the track made up of permanent magnets. Type-II superconductor affixed on the bottom side of the ship body and along its both side to generate an extreme magnetic field and makes it capable of traveling at high speed taking huge loads of passengers, weapon, and aircraft. Cryogenic system is set up on the ship to maintain the superconductivity state. Multiple external power system is there on the ship. There are long pipes in the ship for exhausting the contaminated air to keep the ship room in fresh condition. The ship is proposed to design large enough to travel with thousands of passengers. There is aircraft on the ship for emergency rescue purpose. It is proposed not to run the ship in the polar area (Arctic and Antarctic) of the earth because 
some magnetic interaction may occur and the functioning of the maglev ship may have interaction with the earth magnetic field leading to degrading the performance of the maglev ship.

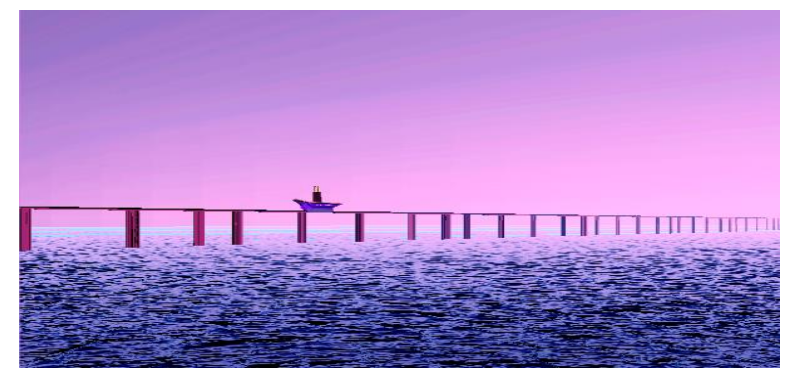

(a)

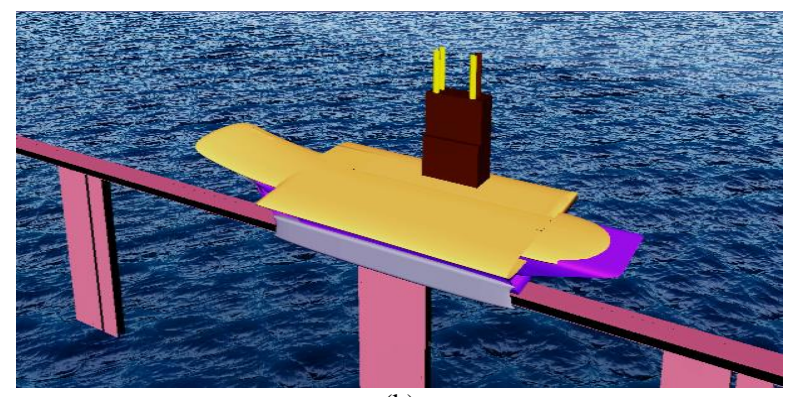

(b)

Fig.2. (a) and (b). Different views of maglev ship floated on the track build on the sea.

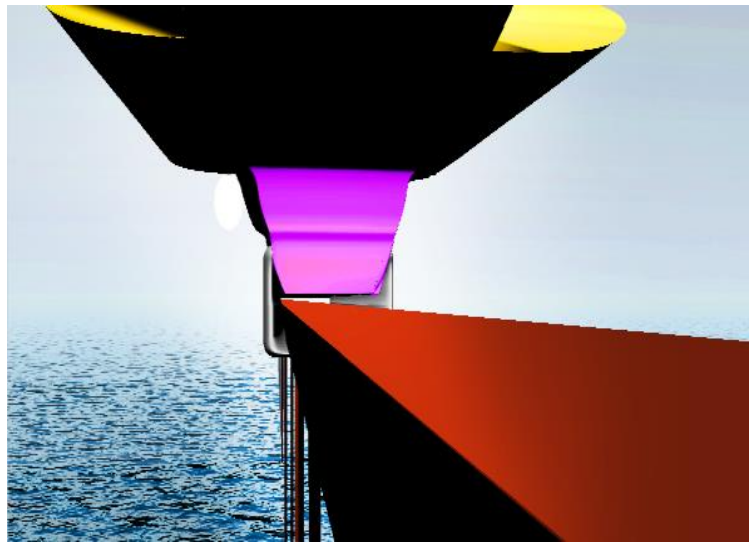

Fig.3. There is a little gap between the maglev ship and the magnetic track.

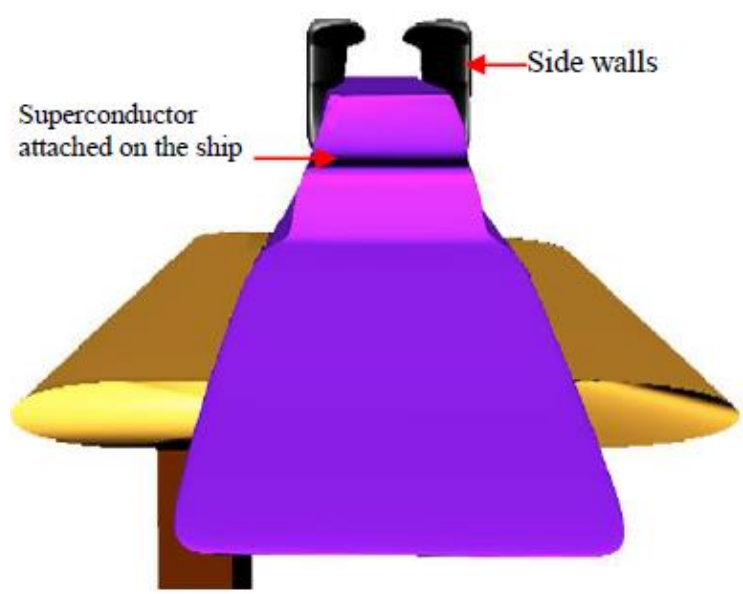

Fig.4. Maglev Ship Bottom Side View.

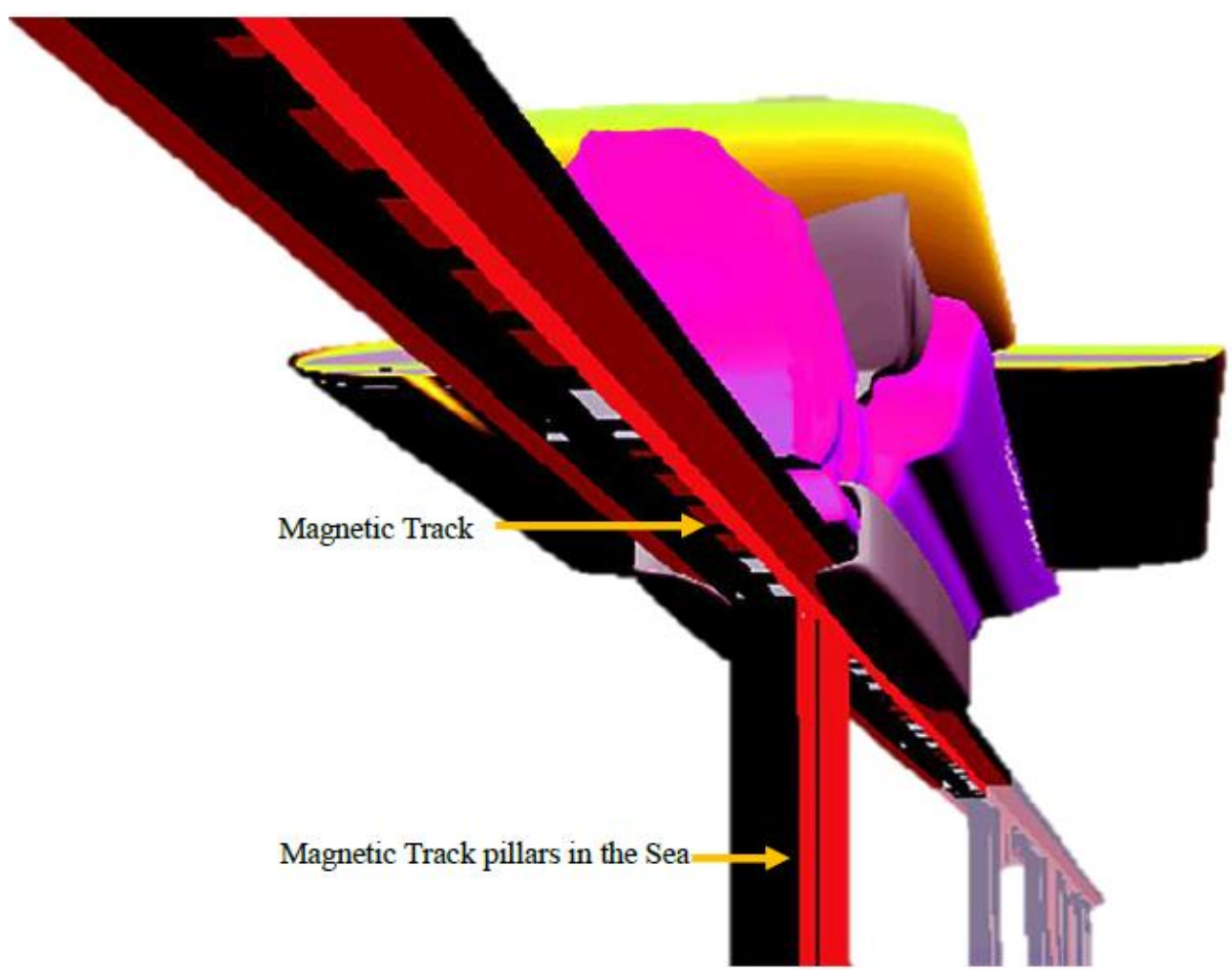

Fig.5. Different Parts of Maglev Ship Track. 


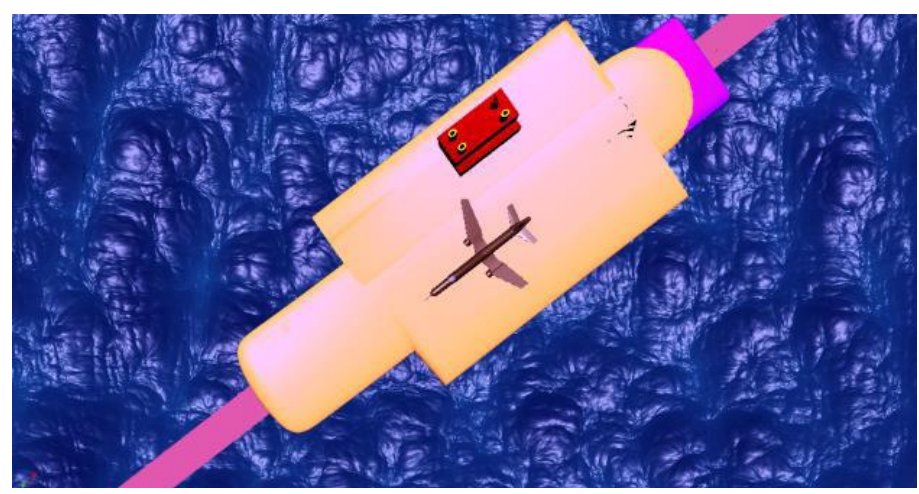

Fig.6. Maglev Ship

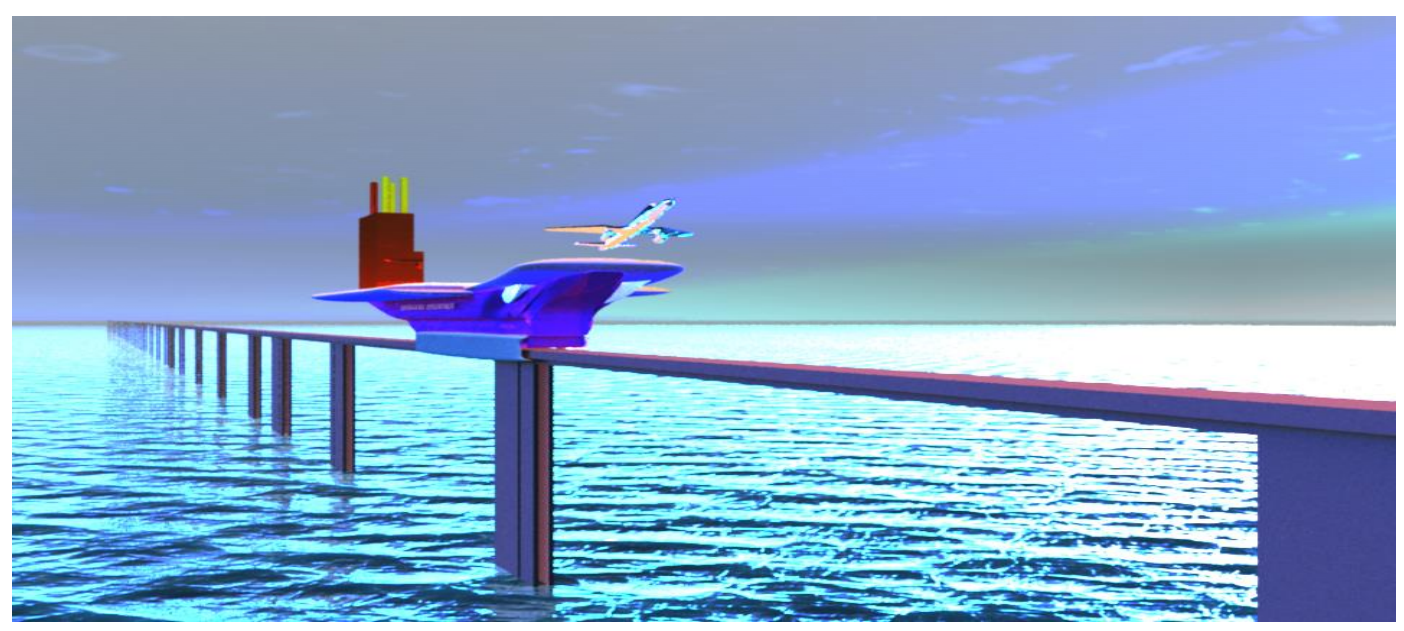

Fig.7. Aircraft take-off from maglev ship for emergency rescue.

Fig. $2-7$, show different parts of the maglev ship, i.e., a maglev track built on the sea where the ship will travel through floating over the track made up of permanent magnets. Type-II superconductor affixed on the bottom side of the ship body and along its both side to generate an extreme magnetic field and makes it capable of traveling at high speed taking huge loads of passengers, weapon, and aircraft. Cryogenic system is set up on the ship to maintain the superconductivity state. Multiple external power system is there on the ship. There are long pipes in the ship for exhausting the contaminated air to keep the ship room in fresh condition. The ship is proposed to design large enough to travel with thousands of passengers. There is aircraft on the ship for emergency rescue purpose. It is proposed not to run the ship in the polar area (Arctic and Antarctic) of the earth because some magnetic interaction may occur and the functioning of the maglev ship may have interaction with the earth magnetic field leading to degrading the performance of the maglev ship.

\section{STUDY WITH COMPUTER VISION}

TABLE II. Maglev Ship Predicted centroid values and its Mean values.

\begin{tabular}{|l|l|}
\hline $\begin{array}{l}\text { Maglev Ship } \\
\text { Components }\end{array}$ & $\begin{array}{l}\text { Guesstimate properties approximate } \\
\text { values }\end{array}$ \\
\hline Ship body & $\begin{array}{l}\text { Steel, iron, plastic, wood, aluminum, } \\
\text { fiberglass, and so forth. }\end{array}$ \\
\hline $\begin{array}{l}\text { Ship Dimension } \\
\text { Length, width, height }\end{array}$ & 1000 foot, 100 feet, 50 feet. \\
\hline Track & $\begin{array}{l}27 \text { miles long. Made of strong } \\
\text { permanent magnets, steel, and iron. }\end{array}$ \\
\hline $\begin{array}{l}\text { Pillars height and } \\
\text { number }\end{array}$ & 150 meters. 7000 pillars \\
\hline Speed & 400 km/hour \\
\hline $\begin{array}{l}\text { Type of superconductor } \\
\text { Type-II superconductor made on } \\
\text { BSCCO. Critical temperature (Tc) is } \\
110 \text { Kelvin. Critical Magnetic Field } \\
\text { Bc >=15 Tesla }\end{array}$ \\
\hline Permanent magnets & Neodymium magnets \\
\hline
\end{tabular}


Table III. Maglev ship predicted centroid values.

\begin{tabular}{|l|l|}
\hline $\begin{array}{l}\text { Maglev Ship } \\
\text { Components }\end{array}$ & $\begin{array}{l}\text { Guesstimate properties approximate } \\
\text { values }\end{array}$ \\
\hline Ship body & $\begin{array}{l}\text { Steel, iron, plastic, wood, aluminum, } \\
\text { fiberglass, and so forth. }\end{array}$ \\
\hline $\begin{array}{l}\text { Ship Dimension } \\
\text { Length, width, height }\end{array}$ & 1000 foot, 100 feet, 50 feet. \\
\hline Track & $\begin{array}{l}27 \text { miles long. Made of strong } \\
\text { permanent magnets, steel, and iron. }\end{array}$ \\
\hline $\begin{array}{l}\text { Pillars height and } \\
\text { number }\end{array}$ & 150 meters. 7000 pillars \\
\hline Speed & 400 km/hour \\
\hline Type of superconductor & $\begin{array}{l}\text { Type-II superconductor made on } \\
\text { BSCCO. Critical temperature (Tc) is } \\
110 \text { Kelvin. Critical Magnetic Field } \\
\text { Bc >=15 Tesla }\end{array}$ \\
\hline Permanent magnets & Neodymium magnets \\
\hline
\end{tabular}

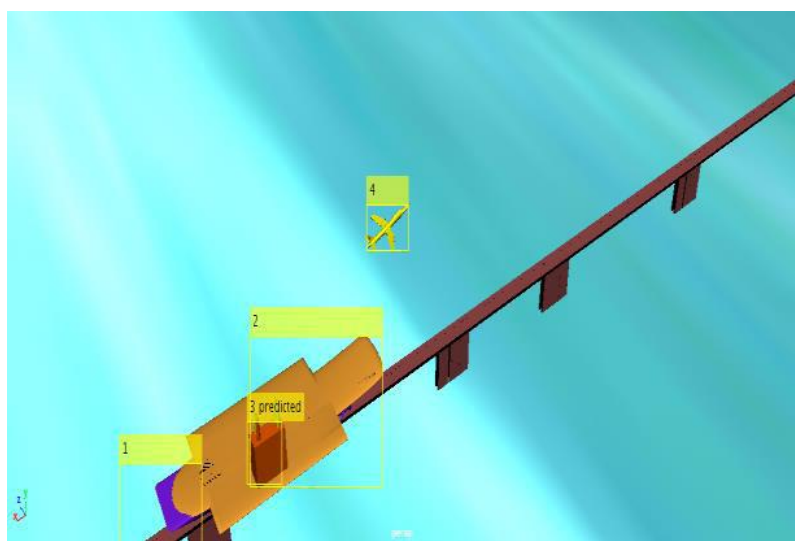

Fig.8. Tracking with Kalman filter.

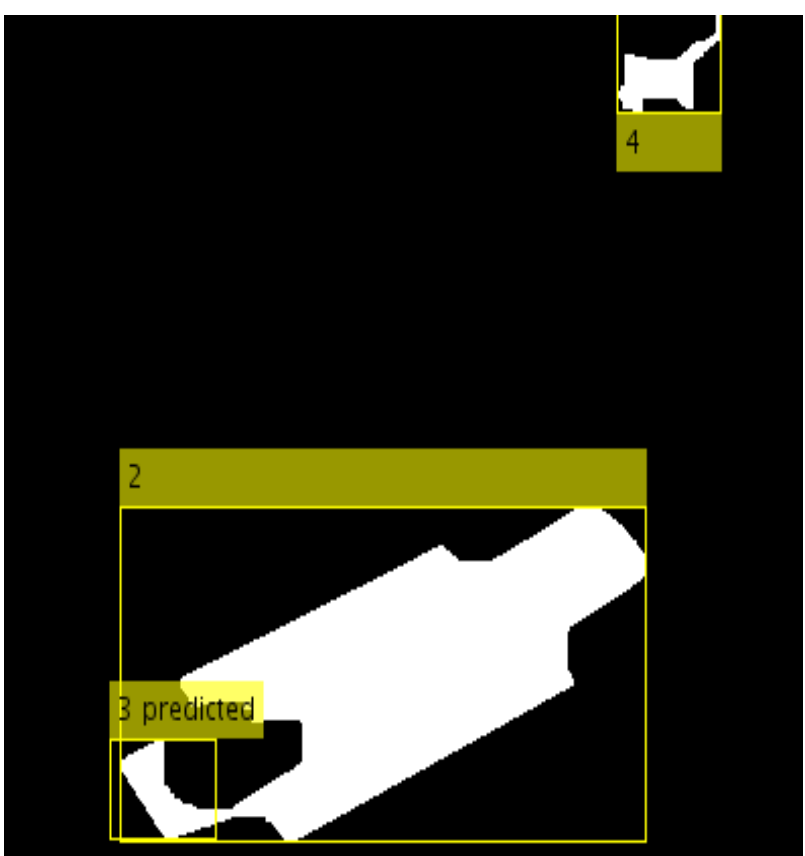

Fig.9. Motion-Based Multiple Object Tracking of maglev ship.

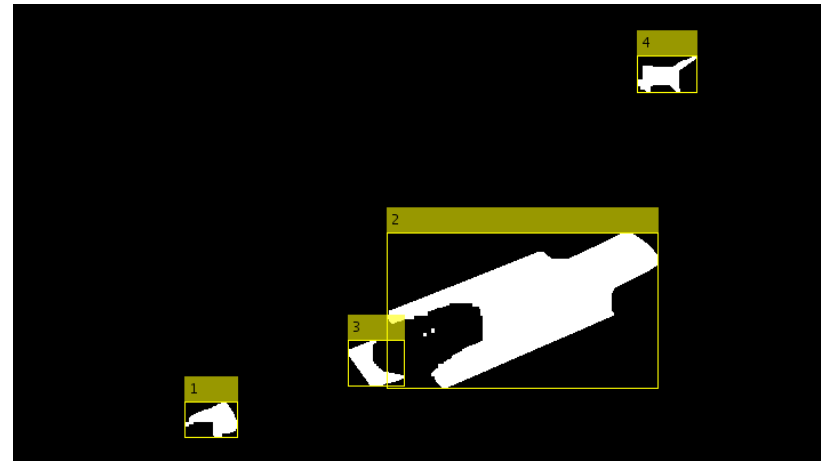

Fig.10. Another scenario from Motion-Based Multiple Object Tracking of the maglev ship.

Automatic detection and motion-based tracking of moving objects on a video is already done in many research articles. There are many computer vision applications like traffic tracking, and automobile protection wherein motion-based monitoring and detection of an object in motion are critical components. The movement-based object monitoring includes following parts: detecting motion objects in video frames or in a photograph and associating the detections corresponding to the identical object over time. The detection of an object in motion applied a background subtraction algorithm based on Gaussian mixture models. Morphological operations are applied to the foreground mask to get rid of noise from the video frames. The blob analysis calculates statistics of connected regions in a binary image. The motion of each track is estimated by a Kalman filter. The filter is used to predict the track's location in each frame and determine the likelihood of each detection being assigned to each track.

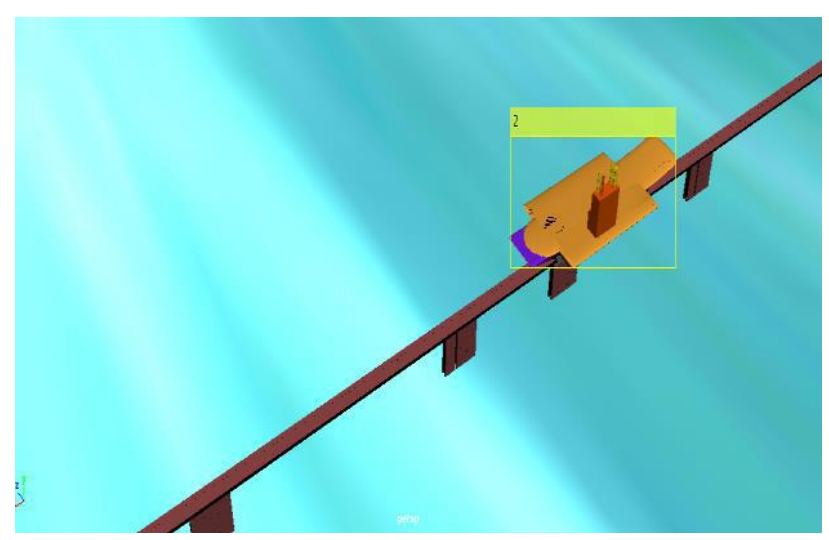

Fig.11. Kalman filter used for Motion-Based Multiple Object Tracking of maglev ship where only one object is detected. 


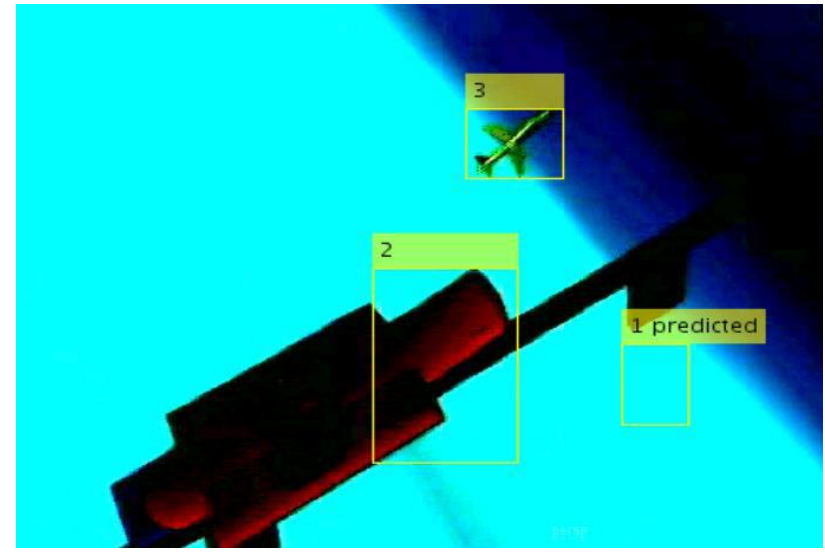

Fig.12. Enhanced vision.

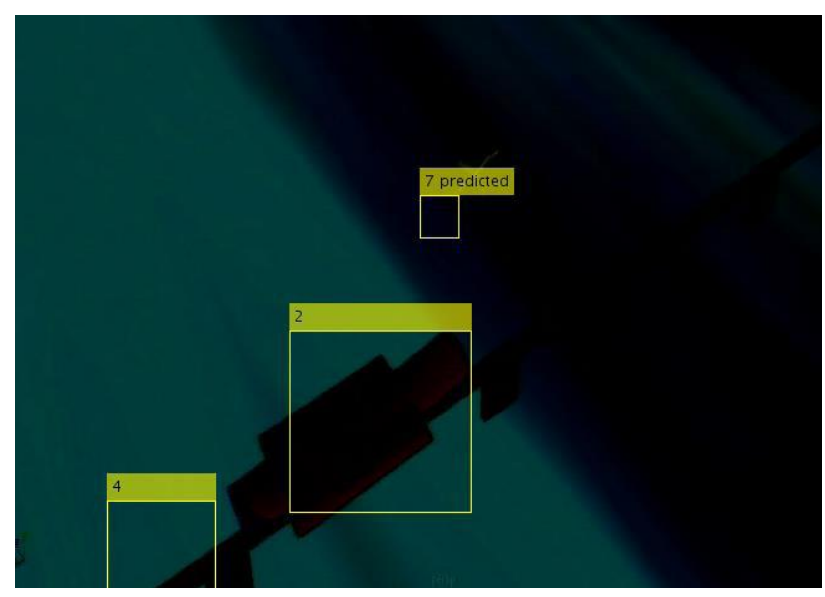

Fig.13. original video frame.

The proposed method:

$$
\begin{aligned}
& \beta=2.9 \\
& \operatorname{emax}=0 ; \\
& \operatorname{emax}=(\beta * \text { frame })+((1-\beta) * \text { emax }) \\
& \text { emay }=(2 * \text { emax })
\end{aligned}
$$

Here beta $(\beta)$ is a tunable parameter for smoothing the intensity value of video frames. We have applied an exponential moving average function on original video frames of the ship animated video. We have multiplied the ema to get the double of exponential moving average function. This animated video is designed and animated in Autodesk Maya animation software. We have tested the result through PSNR, MSE and MAXERR functions and found that the proposed method gives better result shown in Table I. we have calculated the average PSNR, MSE, and MAXERR. We get higher PSNR value from the proposed methods which indicate better result and lower mean square error and lower MAXERR from the proposed method which indicates the better result. The elapsed running time to detect multiple objects using the proposed method is faster compared to the original method. The average running time of proposed method is less compare to the original method.

\begin{tabular}{|c|c|}
\hline Functions Description [14] & Formula and explanation \\
\hline $\begin{array}{l}\text { Mean squared normalized } \\
\text { error performance function } \\
\text { (MSE). The mean square } \\
\text { error between a signal or } \\
\text { image, X, and an } \\
\text { approximation, Y, is the } \\
\text { squared norm of the } \\
\text { difference divided by the } \\
\text { number of elements in the } \\
\text { signal or image. }\end{array}$ & $M S E=\frac{\|X-Y\|^{2}}{N}$ \\
\hline $\begin{array}{l}\text { Peak Signal to Noise Ratio } \\
\text { (PSNR) in decibels (dB). }\end{array}$ & $\begin{array}{l}10 \log _{10}\left(\frac{R^{2}}{M S E}\right) \\
\text { If input image data type is the } \\
\text { double precision floating point, } \\
\text { the } \mathrm{R} \text { is } 1 . \text { If the input image is } \\
\text { an 8-bit unsigned integer, the } \mathrm{R} \\
\text { is } 255 \text {. }\end{array}$ \\
\hline $\begin{array}{l}\text { MAXERR is the maximum } \\
\text { absolute squared deviation } \\
\text { of the data, X, from the } \\
\text { approximation, XAPP. }\end{array}$ & $\begin{array}{l}\text { XAPP is a real-valued signal or } \\
\text { image approximation with a } \\
\text { size equal to that of the input } \\
\text { data, } X . X \text { is a real-valued } \\
\text { signal or image. }\end{array}$ \\
\hline
\end{tabular}

Table IV. Average PSNR, MSE, and MAXERR.

\begin{tabular}{|l|l|l|l|l|}
\hline & $\begin{array}{l}\text { Average } \\
\text { PSNR }\end{array}$ & $\begin{array}{l}\text { Average } \\
\text { MSE }\end{array}$ & $\begin{array}{l}\text { Average } \\
\text { MAXERR }\end{array}$ & $\begin{array}{l}\text { Average } \\
\text { Runtime }\end{array}$ \\
\hline $\begin{array}{l}\text { Original } \\
\text { Method }\end{array}$ & 48.738 & 0.8712 & 1 & $\begin{array}{l}35.042057 \\
\text { seconds }\end{array}$ \\
\hline $\begin{array}{l}\text { Proposed } \\
\text { Method }\end{array}$ & 49.881 & 0.6683 & 1 & $\begin{array}{l}32.073264 \\
\text { seconds }\end{array}$ \\
\hline
\end{tabular}

Table V. Functions Description.

\section{CONCLUSION}

The present study has dealt with a ship run by magnetic levitation technology. The new ship design has been proposed by following the structure of maglev train and warship with an ability to voyage with a large number of passengers in a short period of time. The underlying setup and establishment expense may turn out to be high, yet the maintenance cost would be lower compared to other conventional ship. The proposed ship is anticipated to be of immense utility for the voyagers for the safe and fast journey in addition to availing the facility to be rescued by airplanes kept on the ship and it may be used in the time of warfare. We have tested the Kalman filter result through PSNR, MSE and MAXERR functions. it is found that the proposed method gives a better result. It is proved that the average running time of optimized Kalman filter produced better result compare to original Kalman filter algorithm.

\section{ACKNOWLEDGMENTS}

The first author is grateful to National Institute of Technology Agartala, India for providing Ph.D. fellowship for carrying out the research work. 


\section{REFERENCES}

[1] Marc T. Thompson; Richard D. Thornton (May 1999). "Flux-Cancelling Electrodynamic Maglev Suspension: Part II Test Results and Scaling Laws". (PDF). IEEE Transactions on Magnetics 35 (3).

[2] Maglev2000.com, maglev2000.com, 'The Water Train', [online].

http://www.maglev2000.com/apps/apps-04-b.html.

[Accessed: 2016, November].

[3] The graphic: maglev train [news briefing], engineering \& technology, volume 10 , issue 5 , pp.16-16, iet journals \& magazines.

[4] Motion-Based Multiple Object Tracking, http://in.mathworks.com/help/vision/examples/motionbased-multiple-object-

tracking.html?searchHighlight=kalman $\% 20$ filtering $\% 20 \mathrm{ob}$ ject\%20tracking\&s_tid=doc_srchtitle

[5] Maya, http://www.autodesk.com/education/free-software

[6] Type II superconductors, http://hyperphysics.phyastr.gsu.edu/HBase/solids/scond.html\#c5.

[7] "principle of maglev." railway technical research institute. retrieved 25 May 2012.

[8] h. Maeda, y. Tanaka, m. fukutumi, and t. Asano (1988). "a new high-tc oxide superconductor without a rare earth element." jpn. j. Appl. phys. 27 (2): 209-1210. bibcode:1988, jajap.271.209m.

[9] The levitating superconductor, http://www.ted.com/talks/boaz_almog_levitates_a_superco nductor.

[10] M. Ono, S. Koga and H. Ohtsuki, "Japan's superconducting Maglev train," in IEEE Instrumentation \& Measurement Magazine, vol. 5, no. 1, pp. 9-15, Mar 2002. doi: $10.1109 / 5289.988732$

[11] Hyung-Woo Lee, Ki-Chan Kim and Ju Lee, "Review of maglev train technologies," in IEEE Transactions on Magnetics, vol. 42, no. 7, pp. 1917-1925, July 2006.

[12] L. Schultz et al., "Superconductivity levitated transport system - the SupraTrans project," in IEEE Transactions on Applied Superconductivity, vol. 15, no. 2, pp. 2301-2305, June 2005. doi: 10.1109/TASC.2005.849636

[13] H. Maeda; Y. Tanaka; M. Fukutumi \& T. Asano (1988). "A New High-Tc Oxide Superconductor without a Rare
Earth Element". Jpn. J. Appl. Phys. 27 (2): L209-L210. Bibcode:1988JaJAP..27L.209M.

[14] Huynh-Thu, Q.Scope of validity of PSNR in image/video quality assessment, Electronics Letters, 44, 2008, pp. 800801 .

\section{Authors' Profiles}

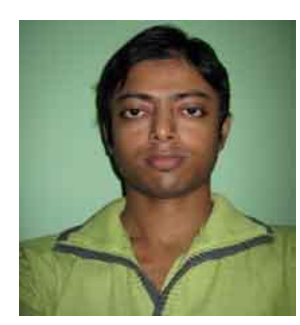

Kuldip Acharya received his M.Tech in Computer Science and Engineering from Tripura University, Tripura, India in 2012. He is doing Ph.D. in Computer Science \& Engineering from National Institute of Technology Agartala, India from 2013. His areas of interest are computer vision, 3D Computer Animation \& design and, image processing.

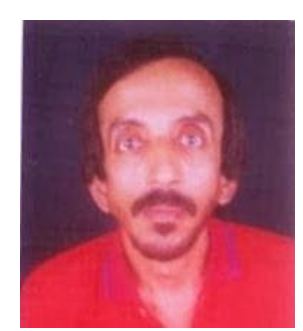

Dibyendu Ghoshal has received his B.Sc. (Honors in Physics), B. Tech \& M. Tech in Radio physics and Electronics, from Calcutta University(CU) in 1981, 1985 and 1987 respectively. He joined Indian Engineering Services (Group-A) in 1988 and served Department of Telecommunication, GOI. After holding various posts for three years, D. Ghoshal left the job to pursue higher studies and was awarded SRF in 1992 by CSIR. Subsequently, he was awarded Postdoctoral Research Associateship in 1996 and Ph.D. in Radio physics \& Electronics from CU in 1997 with specialization in Microwave and millimeter wave systems. D. Ghoshal has served as a postdoctoral research associate and scientist for nearly 12 years and was associated with various projects sponsored by GOI. His research interest includes micro \& millimeter wave, semiconductor physics \& devices, Digital Image Processing, computer vision and computer animation.

How to cite this paper: Kuldip Acharya, Dibyendu Ghoshal," Three Dimensional Modeling and Animation of a New Maglev Ship and Its Study with Computer Vision ", International Journal of Image, Graphics and Signal Processing(IJIGSP), Vol.10, No.5, pp. 56-63, 2018.DOI: 10.5815/ijigsp.2018.05.06 